\title{
Ein neues Buch zu Nahtoderfahrungen
}

Hedi Meierhans

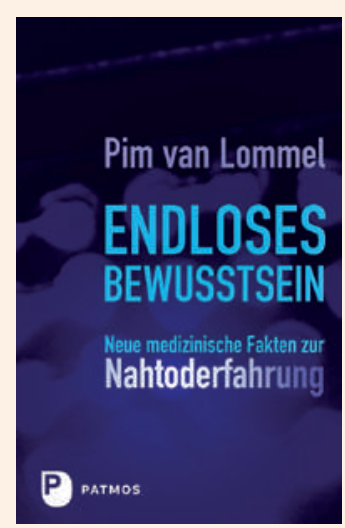

Pim van Lommel Endloses Bewusstsein Neue medizinische Fakten zur Nahtoderfahrung Ostfildern: Schwabenverlag; 2011

440 Seiten. $27.90 \mathrm{CHF}$ ISBN 978-3-8436-0013-2

Korrespondenz:

Dr. med. Hedi Meierhans

Solenberg 38

CH-8723 Maseltangen

Tel. 0552832224

hedi.meierhans[at]hin.ch

\section{Der Autor}

Pim van Lommel, geb. 1943, wuchs in den Niederlanden in einer Arztfamilie auf, geprägt von einem naturwissenschaftlichen Konzept der Medizin. Er wurde Leitender Kardiologe am Rijnstate Krankenhaus in Arnheim. Seit 1986 untersuchte er Nahtoderfahrungen aus wissenschaftlicher Sicht. Im Dezember 2001 veröffentlichte er in The Lancet eine prospektive Studie über Nahtoderfahrungen (NTE) mit 344 Patienten. 18\% der Patienten berichteten über gewisse Erinnerungen und Erfahrungen, die sie im Zeitraum des klinischen Todes erlebten. Es zeigte sich, dass psychologische, pharmakologische und physiologische Faktoren diese Erfahrungen nicht erklären konnten, die während eines Herzstillstandes geschahen. Aufgrund seiner Studien zur NTE ist van Lommel zur Überzeugung gekommen, dass das Bewusstsein weder an eine bestimmte Zeit noch an einen bestimmten Ort gebunden ist. Unser Gehirn hat eine vermittelnde statt einer produzierenden Funktion für das Erleben von Bewusstsein. Die Schlussfolgerung, dass es eine Kontinuität des Bewusstseins gibt, weil man Bewusstsein unabhängig von der Hirnfunktion erfahren kann, könnte in der westlichen Wissenschaft zu einem Paradigmenwechsel führen (Auszug aus seiner Homepage).

\section{Wie alles begann}

Erst als er persönlich mit dem Tod zweier Familienmitglieder konfrontiert wurde, begann Pim van Lommel, sich ernsthaft mit Gedanken über den Tod und das «Danach» zu befassen. 1986 las er ein Buch von George Ritchie über Nahtoderfahrungen. Dieser war als Medizinstudent 1943 neun Minuten klinisch tot. Man deckte ihn schon zu. Durch das Bitten eines erschütterten Pflegers um eine Adrenalinspritze auf Herzhöhe konnte er zurückgeholt werden und machte eine tiefgreifende Nahtoderfahrung.

\section{Persönliche Eindrücke und Gedanken zum Buch}

Ich habe schon viel über Nahtoderfahrungen (NTE) gelesen, aber dieses Buch ist das erste mit einer prospektiven Studie, die so wissenschaftlich und exakt verfasst wurde, wie es zurzeit möglich ist. Die grösste Herausforderung für Pim van Lommel ist die Suche nach einer Erklärung, wie die Wahrnehmung eines erweiterten Bewusstseins möglich ist. Er vermittelt Tatsachen aus dem Wissensstand verschiedener Forschungsgebiete wie z.B. der Neurophysiologie und der Quantenphysik. Faszinierend für mich ist, wie er die Schnittstellen Gehirn-Bewusstsein, Junk DNA - nichtlokales Bewusstsein, herauskristallisiert. Er definiert den nichtlokalen Raum, ursprünglich nur Begriff in der Quantenphysik: Raum, in dem Zeit und Distanz keine Rolle spielen, wo alles augenblicklich und ständig miteinander verbunden ist. Im nichtlokalen Raum gibt es eine verborgene Wirklichkeit, die fortwährend Einfluss auf unsere physische Welt ausübt. Bei diesen Schnittstellen spielen Resonanzphänomene eine wichtige Rolle. Meines Erachtens ist Resonanz das grosse Zauberwort in der Forschung: im ganzen Leben, im Sein, im Körper und in der Psyche. Dass das Gehirn als Sender/Empfänger funktioniert, habe ich schon oft erlebt. Nach Pim van Lommel enthält das Bewusstsein potentielle Informationen, die im nichtlokalen Raum als Wellenfunktionen gespeichert sind. Es übermittelt Informationen an das Gehirn und empfängt vom Gehirn Informationen aus dem Körper und den Sinnesorganen.

\section{Ich finde, dass die Nervenzellen so wenig Gedanken produzieren wie die Herzmuskelzellen Liebe.}

Ich finde, dass die Nervenzellen so wenig Gedanken produzieren wie die Herzmuskelzellen Liebe.

Das Studium der Nahtoderfahrungen hat nicht nur eine grosse Bedeutung für das Verständnis des Todes oder von Sterbeprozessen, sondern verhilft auch im Leben, die richtigen Prioritäten zu setzen, und motiviert, schwierige Situationen durchzuhalten. Pim van Lommel hat auch die Auswirkungen auf das Leben der Menschen mit Nahtoderfahrungen geprüft, indem er sie nach zwei resp. acht Jahren nochmals befragte.

Van Lommel hat den Nahtoderfahrungen zwölf Elemente zugeordnet. Er hat die Beispiele so ausgewählt, dass zu jedem Element der NTE ein Beispiel besonders passt.

\section{Beispiele von Nahtoderfahrungen}

Was mich sehr beeindruckt hat, sind folgende Nahtoderfahrungen, die van Lommel erwähnte: 


\section{Zum Element «Strahlendes Licht»}

«(...) wo ich in das Gefühl vollkommener Liebe eintauchte. Mir war plötzlich glasklar bewusst, warum ich Krebs bekommen hatte. Und vor allem, warum man mich in dieses Leben gestellt hatte. Welche Rolle jeder einzelne Angehörige in meinem Leben spielte, in Bezug auf den grossen Plan, in dem alles festliegt, und auf das allgemeine Wesen des Daseins. Ich besass in diesem Zustand eine Klarheit und Einsicht, die einfach unbeschreiblich ist. Worte scheinen diese Erfahrung nur einzuengen ...»

«Im gleichen Augenblick durchdrang mich mit einem Schlag eine ungeheure Erkenntnis, ein umfassendes Wissen und Verstehen. Alles Wissen. Universales Wissen. Ich verstand, wie das Weltall entstanden war, woraus das Universum bestand. Alles und jedes entfaltet und entwickelt sich gemeinsam. Ich sah und verstand - ohne zu urteilen - den Zusammenhang, die Kohärenz, die logische und manchmal weitreichende Konsequenz, die jede noch so kleine Handlung hat. Und zwar auf jeder Ebene bis ins kleinste Detail: Funktion aller möglichen mechanischen, elektrischen und elektronischen Geräte, Apparate und Motoren. Alles. Ich kannte und verstand die gesamte Mathematik, die Elektronik, die Physik, die DNA, die Atome, die Quantenmechanik und Quantenphysik. Ich erkannte auch, worauf alle Evolution hinausläuft. Worin letzten Endes ihr Ziel liegt. Mir wurde bewusst, dass nicht nur ich Teil dieser grossen Einheit bin, sondern alles und jeder, jeder Mensch, jedes beseelte Wesen, jedes Tier, jede Zelle, die Erde und jeder andere Planet, das Universum, der Kosmos, das Licht. Alles ist miteinander verbunden, alles untrennbar. «Ich weiss es), dachte ich froh, ich verstehe es.> Es ist alles so einfach. So logisch. So naheliegend ... Nein, dieses Wissen durfte ich nicht hinüberbringen. Warum weiss ich nicht. Vielleicht liegt der Sinn nicht darin, dass wir hier und jetzt als physische Wesen über derlei universelles Wissen verfügen? Weil wir hier sind, um zu lernen? Oder aus einem andern Grund?»

\section{Zum Element «Lebensschau oder Rückblick»}

«Mein ganzes Leben bis zum heutigen Tag schien sich in einer Art panoramaartigem dreidimensionalem Rückblick vor mir auszubreiten. Jedes Ereignis wurde von einem Wissen über Gut und Böse oder der Einsicht in seine Ursachen und Folgen begleitet. Ich betrachtete alles nicht nur ausschliesslich aus meiner Warte, sondern kannte auch die Gedanken aller anderer, die an diesem Ergebnis beteiligt waren, als wären ihre Gedanken in mir. Ich konnte nicht nur sehen, was ich getan und gedacht hatte, sondern sogar wie mein Handeln andere beeinflusst hatte als sähe ich mit allwissenden Augen. Auch die Gedanken gehen nicht verloren. Und immerfort wurde während des Rückblicks die Bedeutung der Liebe bezeugt. Ich war überall gleichzeitig, manchmal wurde meine Aufmerksamkeit auf etwas gelenkt und schon war ich dort.»

\section{Zum Element «ausserkörperliche Erfahrung»}

Die Schilderung einer Frau, die von Geburt an blind ist:

«Ich habe niemals auch nur das Geringste gesehen, kein Licht, keinen Schatten, überhaupt nichts. Sehr viele Leute fragen mich, ob ich Schwarz sehen kann. Ich sehe überhaupt nichts. Auch in meinen Träumen habe ich keine visuellen Eindrücke. Dort gibt es nur Geschmack, Gefühl, Geräusch und Geruch.

Zunächst kann ich mich daran erinnern, dass ich im Harbour View Medical Center war und auf alles herabschaute. Es war beängstigend, denn ich war es nicht gewohnt, etwas visuell wahrzunehmen, das war mir vorher noch nie passiert! Am Anfang war alles ziemlich unheimlich! Aber dann erkannte ich meinen Ehering und mein Haar. Und ich dachte: Ist das mein Körper da unten? Bin ich etwa tot?) Sie schrien immer wieder: 'Wir können sie nicht zurückholen, wir können sie nicht zurückholen!) Und (...) sie arbeiteten wie besessen an diesem Ding, von dem ich jetzt wusste, dass es mein Körper war, obwohl er mir eigentlich nichts bedeutete. Ich hatte so ein Gefühl von «Na und? und dachte nur: 〈Warum regen die sich eigentlich so auf? Ich beschloss fortzugehen, denn ich konnte diese Leute einfach nicht dazu bringen, mir zuzuhören. Allein schon beim Gedanken bewegte ich mich nach oben, quer durch die Decke, als ob sie gar nicht da wäre. Es war fantastisch, draussen zu sein, mich frei zu fühlen und mir keine Sorgen machen zu müssen, wogegen ich dieses Mal wieder stossen würde. Ich wusste auch, wohin ich unterwegs war. Ich hörte einen rauschenden Klang wie von einem Windgong, es war der unglaublichste Klang, den man sich vorstellen konnte - er war vom tiefsten bis zum höchsten Ton zu hören. Als ich mich diesem Gebiet näherte, waren Bäume, Vögel und viele Menschen dort, aber sie wirkten wie Lichtgebilde. Und ich konnte sehen. Es war unglaublich, wirklich fantastisch, ich war über- 
wältigt von dieser Erfahrung, denn schliesslich hatte ich nie eine Vorstellung gehabt, was Licht eigentlich ist. Es gab einen Moment, in dem ich fühlte, dass mir, wenn ich nur wollte, alles Wissen offenstand (...) Und in dieser anderen Welt ssah > ich einige Bekannte, die mich willkommen hiessen. Insgesamt waren es fünf. Debby und Diane waren früher meine Schulfreundinnen, aber sie waren schon vor langer Zeit gestorben, in einem Alter von 11 und 6 Jahren. Als sie noch lebten, waren sie beide minderbegabt und blind. Hier aber «sahen s sie strahlend, schön, vital und gesund aus. Sie waren offenbar keine Kinder mehr, sondern standen in der Blüte ihres Lebens. Ausserdem «sah» ich zwei der Betreuer aus meiner Kindheit wieder, ein Ehepaar, Herr und Frau Zilk hiessen sie, auch sie waren beide verstorben. Schliesslich war da noch meine Oma, bei der ich eigentlich aufgewachsen war. Sie war zwei Jahre vor diesem Unfall von uns gegangen. Meine Oma, die ein wenig abseits stand, streckte die Arme nach mir aus, um mich zu umarmen (...) Und dann wurde ich zurückgeschickt ...»

\section{«Im gleichen Augenblick durchdrang mich mit einem Schlag eine ungeheure Erkenntnis, ein umfassendes Wissen und Verstehen.»}

Dann die Schilderung eines Pflegers: «Als ich die Beatmung übernehme und den Patienten intubieren will, fällt mir auf, dass er noch ein künstliches Gebiss trägt. Vor der Intubation entferne ich den oberen Teil der Prothese und lege sie auf den Instrumentenwagen. In der Zwischenzeit setzen wir die Massnahmen zur erweiterten Reanimation fort. Nach etwa anderthalb Stunden hat der Patient zwar wieder einen ausreichend stabilen Herzrhythmus und Blutdruck, er wird aber noch beatmet, ist noch intubiert und noch immer komatös. In diesem Zustand wird er zur weiteren Beatmung auf die Intensivstation gebracht. Erst eine Woche später, bei der Medikamentenausgabe, begegne ich dem Patienten, der gerade wieder auf die Kardiologie verlegt wurde, wieder. Als er mich sieht, sagt er: «Oh, dieser Pfleger weiss, wo mein Gebiss liegt.> Ich bin ganz überrascht, doch er erklärt mir: Ja, sie waren doch dabei, als ich ins Krankenhaus kam, und haben mir das Gebiss aus dem Mund genommen und es auf einen Wagen gelegt, auf dem alle möglichen Flaschen standen. Er hatte so eine ausziehbare Schublade und in die haben sie meine Zähne gelegt.> Das erstaunte mich vor allem deshalb, weil sich dies meiner Erinnerung nach alles zu einer Zeit abgespielt hatte, als der Patient im tiefen Koma lag und gerade reanimiert wurde. Weitere Nachfragen ergaben, dass er damals selbst sehen konnte, wie er im Bett lag, und dass er von oben auf die Pflegekräfte und die Ärzte herab sah, die ihn mit aller Kraft zu reanimieren versuchten. Er konnte auch den kleinen Raum, in dem er wiederbelebt wurde, und das Aussehen der Anwesenden korrekt beschreiben (...) Er schilderte mir, wie er erfolglos zu signalisieren versuchte, dass er noch lebe und wir ihn weiter reanimieren sollten. Er war tief bewegt von dem, was er damals erlebt hatte, und sagte, dass er sich heute nicht mehr vor dem Tod fürchte.»

\section{Forschungsprogramm zu Nahtoderfahrungen} Aus Platzgründen will ich keine weiteren Beispiele mehr anfügen. Nach dem Lesen des sehr berührenden Berichtes der Nahtoderfahrung von George Ritchie: «Rückkehr von morgen», ist mir aufgefallen, dass diese im Jahr 1943 erlebte Erfahrung noch viel symbolischer ist als die heutigen. Man sieht einen Bewusstseinswandel in Richtung grösseres Abstraktionsvermögen bei gleichem Inhalt. Ich möchte noch erwähnen, dass nur 18\% der Patienten sich an eine NTE erinnern können. Ich könnte mir aber vorstellen, dass alle komatösen Patienten eine Nahtoderfahrung machen, aber die meisten wissen es nicht mehr. Wir träumen ja auch jede Nacht und wissen es häufig nicht mehr am Morgen. Die Träume, die jedoch immer erinnert werden, sind Angstträume. Ich glaube, dass die Erinnerungsfähigkeit mit der Intensität der Gefühle zusammenhängt. Das könnte auch bei den Nahtoderfahrungen so sein, obwohl das Traumbewusstsein ein anderes ist als das bei einer NTE, aber die Bedingungen für das Eintreten in das Wachbewusstsein könnten dieselben sein. Bei den Erwachsenen ist es aber so, dass nur diejenigen, die sich an eine NTE erinnern, eine Transformation machen. Auch eine intakte Gedächtnisfunktion müsste vorhanden sein. Dies alles müsste aber weitere Forschung zeigen. Interessant finde ich auch, dass die Erfahrungen der Patienten auch mit ihren Interessen zusammenhängen, sie sind dort, wo ihre Aufmerksamkeit ist. Ich könnte mir auch vorstellen, dass die einen Menschen das Erfahrene nicht einordnen können, es nicht in ihre Vorstellungen passt und sie es darum wieder vergessen.

Für Ärzte und das Pflegepersonal finde ich es besonders wichtig, wenn sie etwas über Nahtoderfahrungen wissen, da laut Studie die Hälfte der Patienten Hilfe bräuchten, der Kenntnisstand der Ärzte und Therapeuten aber gering ist. Dieses Wissen hat vor allem für das Leben in den meisten Bereichen eine grosse Bedeutung. Es wäre schön, wenn die Schweizer Regierung einen Forschungsauftrag für Nahtoderfahrungen erteilen würde. Dies wäre ein sehr wichtiger Anteil zur Bewusstseinsforschung und zu dringend nötigen neuen Entwicklungen. Ich suche daher Ärzte, die mit mir ein solches Forschungsprogramm auf die Beine stellen würden. Für eine effiziente Studie bräuchte es mindestens sechs grosse Kliniken.

Ich bin Pim van Lommel sehr dankbar für dieses Buch, die riesige Arbeit, die er geleistet hat, und das immer noch sehr grosse Engagement. 